\title{
Manumycin A from a new Streptomyces strain induces endoplasmic reticulum stress-mediated cell death through specificity protein 1 signaling in human oral squamous cell carcinoma
}

\author{
JUNG JAE CHO ${ }^{1 *}$, JUNG-IL CHAE ${ }^{2 *}$, KA HWI KIM $^{1}$, JIN HYOUNG CHO ${ }^{2}$, YOUNG-JOO JEON $^{2}$, HA NA OH $^{1}$, \\ GOO YOON $^{1}$, DO YOUNG YOON ${ }^{3}$, YOUNG SIK CHO ${ }^{4}$, SEUNG-SIK CHO ${ }^{1}$ and JUNG-HYUN SHIM ${ }^{1}$ \\ ${ }^{1}$ Department of Pharmacy, College of Pharmacy and Natural Medicine Research Institute, Mokpo National University, \\ Jeonnam 534-729; ${ }^{2}$ Department of Dental Pharmacology, School of Dentistry and Institute of Oral Bioscience, \\ BK21 plus, Chonbuk National University, Jeonju 651-756; ${ }^{3}$ Department of Bioscience and Biotechnology, \\ Bio/Molecular Informatics Center, Konkuk University, Seoul 143-701; ${ }^{4}$ College of Pharmacy, \\ Keimyung University, 1000 Sindang-dong, Dalseo-gu, Daegu 704-701, Republic of Korea
}

Received May 11, 2015; Accepted July 10, 2015

DOI: $10.3892 /$ ijo.2015.3151

\begin{abstract}
Manumycin A (Manu A) is a natural antibiotic produced by new Streptomyces strain, exhibiting antitumor and anticancer effects. However, the anticancer effects of Manu A on oral squamous cell carcinoma (OSCC) have not been reported. OSCC is an aggressive type of cancer because of its poor prognosis and low survival rate despite advanced medical treatment. We observed that Manu A reduced cell growth and Sp1 protein levels in OSCC cell lines (HN22 and HSC4) in a dose- and time-dependent manner. We also observed downregulation of Sp1 downstream target genes such as p27, p21, Mcl-1 and survivin. Moreover, nuclear staining with DAPI showed that Manu A was able to cause nuclear
\end{abstract}

Correspondence to: Dr Jung-Hyun Shim or Dr Seung-Sik Cho, Department of Pharmacy, College of Pharmacy, Mokpo National University, 1666 Youngsan-ro, Muan-gun, Jeonnam 534-729, Republic of Korea

E-mail: s1004jh@gmail.com

E-mail: sscho@mokpo.ac.kr

${ }^{*}$ Contributed equally

Abbreviations: OSCC, oral squamous cell carcinoma; Manu, manumycin; Sp1, specificity protein 1; DMEM, Dulbecco's modified Eagle's medium; FBS, fetal bovine serum; PBS, phosphate-buffered saline; Mcl-1, myeloid cell leukemia-1; PARP, poly(ADP-ribose) polymerase; P/S, penicillin and streptomycin; MTS, (3-(4,5-dimethylthiazol-2-yl)-5-(3-carboxymethoxyphenyl)-2-(4-sulfophenyl)2H-tetrazolium); DAPI, 4'-6-diamidino-2-phenylindole; PI, propidium iodide

Key words: manumycin A, apoptosis, specificity protein 1, oral squamous cell carcinoma, endoplasmic reticulum stress-mediated cell death condensation and further fragmentation. Flow cytometry analyses using Annexin $\mathrm{V}$ and propiodium iodide supported Manu A-mediated apoptotic cell death of OSCC cells. Furthermore, Bcl-2 family such as mitochondrial pro-apoptotic Bax, anti-apoptotic Bcl-xl and Bid were regulated by Manu A, triggering the mitochondrial apoptotic pathway. In conclusion, these results indicate that Manu $\mathrm{A}$ is a potential to treat human OSCC via cell apoptosis through the downregulation of Sp1.

\section{Introduction}

Oral cancer, which occurs in oral cavity and oropharynx, is a leading cause of cancer-related death and approximately 263,900 new cases were reported and approximately 128,000 of the patients died of oral cancer in 2011, in USA (1). Oral cancer is one of most common types of cancer and over 500,000 patients suffer from it every year (2). Oral squamous cell carcinoma (OSCC) which occurs in the lining of the epithelial cell represents approximately $95 \%$ of head and neck cancer and is the sixth most common malignant neoplasm worldwide (3-5). This aggressive epithelial malignancy has a poor diagnosis and the incidence rate of oral cancer has been elevated up to $50 \%$ over the past two decades, with only a $50 \%$ 5-year survival rate in patients with OSCC despite advanced medical treatment (6-10). There are many chief factors for OSCC, including tobacco, alcohol, and HPV infection (11-13). In addition, it was reported that bacterial infections are associated with tumor site of OSCC because of their ability to induce chronic inflammation.

Manumycin A (Manu A), a product of Streptomyces parvulus, is a natural antibiotic and is known to be a potential tumoricide. Many studies have demonstrated that Manu A inhibits cell viability and induces cell apoptosis in many cancers, such as prostate cancer, multiple myeloma, anaplastic thyroid cancer and colon cancer (14-17). Taking into consideration of possible correlation of bacterial infection to OSCC, 
it is proposed that capability of Manu A to directly suppress some prevalent bacteria (18) has also anticancer effect on OSCC.

To induce apoptosis of cancer cells by targeting the specific signal-transduction pathway could be an effective anticancer therapy. Therefore, we investigated whether the Manu A-induced cell apoptosis is related to Specificity protein 1 (Sp1), a transcription factor that binds to a specific DNA sequence, overexpressed in many cancer cells, such as bladder cancer (19), breast cancer $(20,21)$, pancreatic cancer (22), gastric cancer (23) and oral cancer (24). Specificity protein $1(\mathrm{Sp} 1)$ has already been examined and plays important physiological roles such as cell cycle regulation, cell proliferation, and cell apoptosis (25). However, the relationship between Manu A treatment and downregulation of Sp1 in OSCC cells has not been studied yet. If Manu A can reduce $\mathrm{Spl}$ expression, it will be a potential candidate material for OSCC therapy. In order to verify its therapeutic effect of Manu A, we investigated the apoptotic effect of Manu A by downregulation of Sp1 levels using the OSCC cell lines HN22 and HSC4.

\section{Materials and methods}

Reagents. All the solvents used in the experiments were of extra pure grade. Hexane, ethyl acetate and acetonitrile were purchased from J.T. Baker (Phillipsburg, NJ, USA). Silica gel for Thin layer chromatography, precoated silica gel plate (Kieselgel 60F254, Merck, NJ, USA) was used. Silica gel for silica gel column, Kieselgel 60 (70-230 mesh, Merck) was used to purify manumycin.

Purification of manumycin A. Streptomyces sp. CS392 was grown on rotary shaker at $180 \mathrm{rpm}$ in Emerson media for 2-3 days at $28^{\circ} \mathrm{C}$. Culture broth (3L) was centrifuged at $6,000 \mathrm{rpm}$ for $20 \mathrm{~min}$. Supernatant was extracted two times with ethyl acetate $(1: 1, v / v)$. The extracted ethyl acetate fraction was evaporated and dried using a rotary evaporator at $50^{\circ} \mathrm{C}$ under reduced pressure. Purification of antibiotic was carried out by silica gel column chromatography $(0.8 \times 15 \mathrm{~cm})$. After washing the column with hexane, active material was eluted from the column with hexane-ethyl acetate (4:1). Active fractions were collected and rechromatographed, using a reverse phase-C18 silica gel column $(1.0 \times 15 \mathrm{~cm})$ with $0.01 \%$ formic acid-acetonitrile (4:6) to give manumycin A.

Cell culture. HN22 and HSC4 are human oral squamous cancer cell lines. HN22 cells were provided by Dankook University (Cheonan, Korea) and HSC4 cells were provided by Hokkaido University (Hokkaido, Japan). HN22 and HSC4 cells were cultured in DMEM containing 10\% heat-inactivated FBS and $100 \mathrm{U} / \mathrm{ml}$ each of penicillin and streptomycin at $37^{\circ} \mathrm{C}$ under $5 \% \mathrm{CO}_{2}$ and humidified condition.

3-(4,5-dimethylthiazol-2-yl)-5-(3-carboxymethoxyphenyl)2-(4-sulfophenyl)-2H-tetrazolium (MTS) assay. The result of the Manu A on HN22 and HSC4 cell viability was observed using the Cell Titer $96^{\circledR}$ AQueous One Solution Cell Proliferation Assay kit (Promega, Madison, WI, USA) according to the manufacturer's instructions. The cells were seeded in 96-well plates, grown for $24 \mathrm{~h}$ and treated with various concentration of Manu A. After treatment with Manu A for 24 and $48 \mathrm{~h}$, MTS solution was added to each well and the plates were incubated for $2 \mathrm{~h}$ at $37^{\circ} \mathrm{C}$. Its absorbance was read using an Enspire Multimode Plate reader (Perkin-Elmer, USA) at $490 \mathrm{~nm}$.

Cell cycle analysis. HN22 and HSC4 cells were seeded and treated with Manu A $(0,2.5,5$, and $10 \mu \mathrm{M})$ for $48 \mathrm{~h}$. The harvested cells were washed with $1 \mathrm{ml}$ PBS and $150 \mu \mathrm{l}$ of Muse $^{\mathrm{TM}}$ Cell cycle reagent (EMD Millipore Corp. USA) was added. Additionally, cells were incubated at RT for $30 \mathrm{~min}$ in the dark. Samples were analyzed by Muse Cell Analyzer (Merck Millipore, Billerica, MA, USA) with Muse Cell cycle kit (Merck Millipore).

(4',6-diamidino-2-phenylindole) DAPI staining. After treatment with Manu A, the cells were harvested by trypsinization. The cells were washed with cold PBS, and fixed in $100 \%$ methanol at room temperature for $20 \mathrm{~min}$. The cells were deposited on slides, stained with DAPI solution $(2 \mu \mathrm{l} / \mathrm{ml})$ and observed through a FluoView confocal laser microscope (FluoView FV10i, Olympus Corp., Tokyo, Japan).

Reverse transcription-polymerase chain reaction ( $R T-P C R)$. To analyze the effect of Manu A on OSCC cell lines, we performed RT-PCR using total RNAs and primers designed for the specific gene. Total RNAs were harvested from OSCC cells treated with or without Manu A using the Total RNA extraction (Life Technologies, Carlsbad, CA, USA). With $2.5 \mu \mathrm{g}$ of RNA, RT-PCR was done using First-strand cDNA synthesis kit (Bioassay Co., Ltd., Korea) according to the kit instructions. We obtained cDNA using actin-specific and Spl-specific primers under the following PCR condition (30 cycles: $1 \mathrm{~min}$ at $95^{\circ} \mathrm{C}, 1 \mathrm{~min}$ at $56^{\circ} \mathrm{C}$ and $1 \mathrm{~min}$ at $72^{\circ} \mathrm{C}$ ). The actin primers used were: forward, $5^{\prime}$-GTG GGG CGC CCC AGG CAC CA-3'; and reverse, 5'-CTC CTT AAT GTC ACG CAC GAT TTC-3'; and the Sp1 primers were: forward, 5'-ATG CCT AAT ATT CAG TAT CAA GTA-3'; and reverse, 5'-CCC TGA GGT GAC AGG CTG TGA-3'. Actin was used as an internal control. The RT-PCR products were visualized with ethidium bromide staining under UV light, after electrophoresis on a $2 \%$ agarose gel.

Annexin V. HN22 and HSC4 cells were seeded and grown for $24 \mathrm{~h}$. After $48 \mathrm{~h}$ from treatment with various concentration of Manu A, cells were harvested by trypsinization for analysis. The cells were analyzed by Muse Cell Analyzer (Merck Millipore) with the Muse Annexin V \& Dead Cell kit (MCH100105, Merck Millipore). The whole process of analysis followed the instructions of the kit. The percentage of apoptotic and necrotic cells was calculated from each triplicate sample by statistical analysis of the dot plot using Muse 1.1.2 analysis software (Merck Millipore).

Western blotting. The lysates of treated cells were generated using PRO-PREP ${ }^{\text {TM }}$ Protein Extraction Solution (iNtRON Biotechnology, Korea), followed by centrifugation and supernatant collection. Proteins were separated using SDS-PAGE gel electrophoresis and transferred onto a polyvinylidene fluoride (PVDF) membrane. After blocking with PBS containing 
A

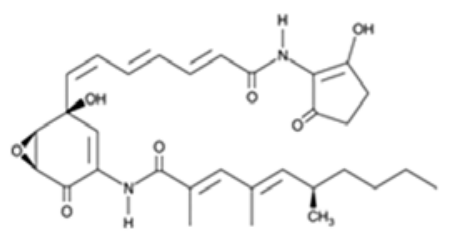

Manumycin A (Manu A)
B

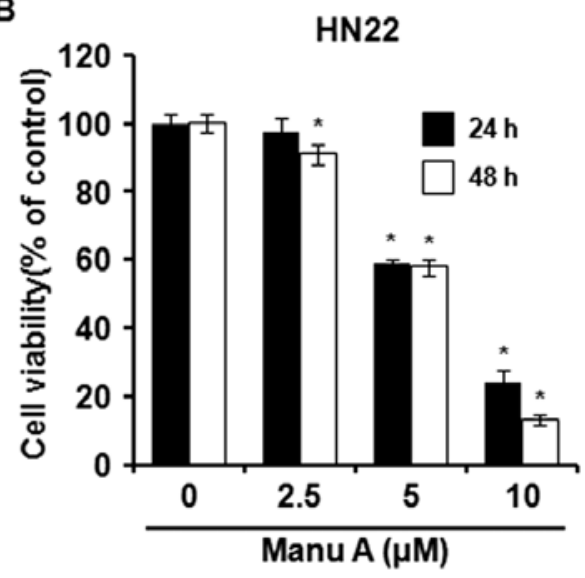

C

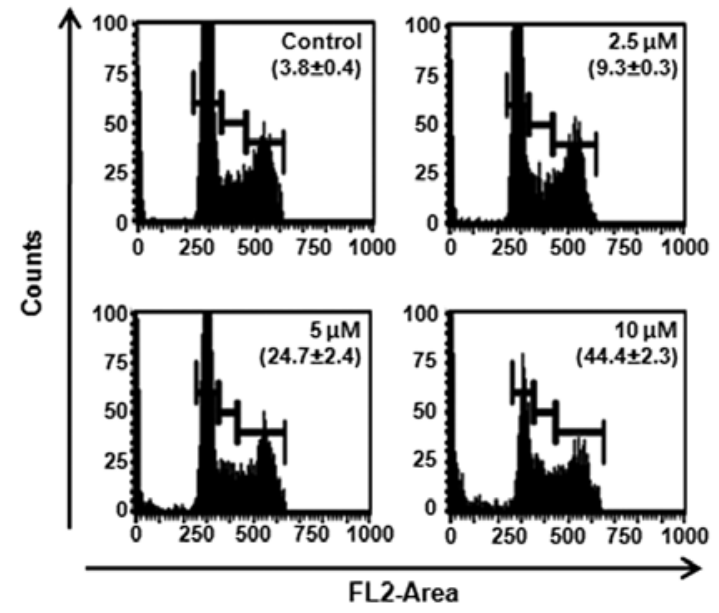

D
HN22

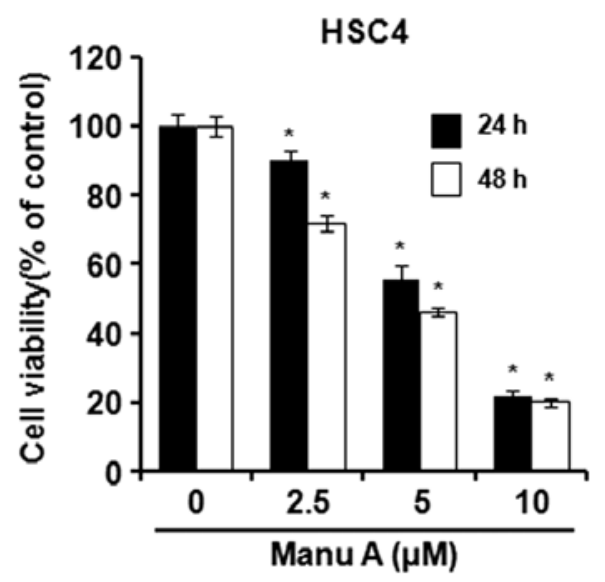

HSC4
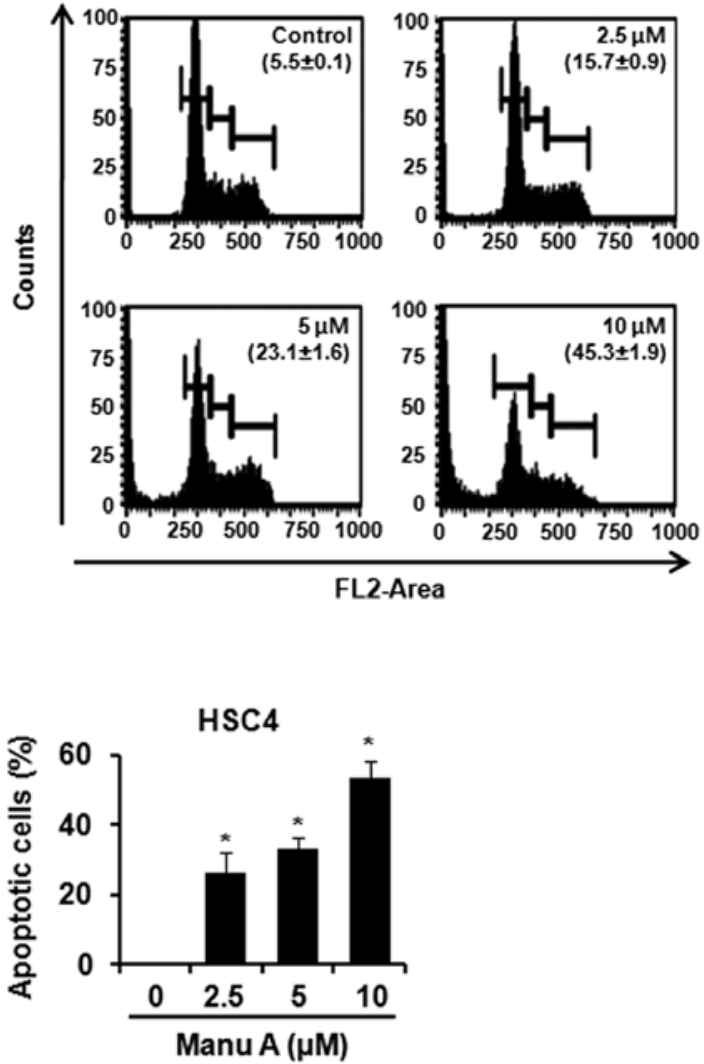

Figure 1. Effect of Manu A on cell viability of OSCC cells. (A) Chemical structure of Manu A. (B) Cell viabilities of HN22 and HSC4 treated with Manu A (2.5, 5 and $10 \mu \mathrm{M}$ ). Cell viability was measured by MTS assay kits. (C) HN22 and HSC4 cells were treated with $2.5,5$ and $10 \mu \mathrm{M}$ of Manu A, and the representative of sub- $\mathrm{G}_{1}$ population was measured by Muse analysis after PI staining. (D) DNA fragmentation and nuclear condensation were quantified using DAPI staining. The data represent the mean percentage levels $\pm \mathrm{SD}(\mathrm{n}=3)$; ${ }^{*} \mathrm{p}<0.05$, significant difference compared with DMSO-treated control cells by paired $t$-test.

$0.1 \%$ Tween-20 and 5\% skim milk, membrane probed with primary antibody was shaken at $4^{\circ} \mathrm{C}$ overnight and then incubated with the secondary antibody. The protein bands were detected using ECL Plus Western Blotting Detection System (Santa Cruz Biotechnology, USA).

Multi-Caspase. The process of the analysis followed the instructions of the Muse Multi-Caspase kit (Muse Cell Analyzer, Merck Millipore). OSCC cells including control and treatment groups were incubated for appropriate time to induce caspase activity and harvested. Cell samples in $1 \mathrm{X}$ caspase buffer with $50 \mu \mathrm{l}$ of Muse Multi-Caspase reagent working solution were incubated at $37^{\circ} \mathrm{C}$ for $30 \mathrm{~min}$, then $150 \mu \mathrm{l}$ of 7 -AAD working solution was added to each sample and triplicate samples were analyzed by Muse Cell Analyzer (Merck Millipore).

Mitochondrial membrane potential assay (MMP). The whole process of the analysis followed the instructions of the Muse MitoPotential kit (Merck Millipore). Control cells and Manu A-treated $(2.5,5$ and $10 \mu \mathrm{M})$ cells were harvested. To investigate the mitochondrial membrane permeability, 

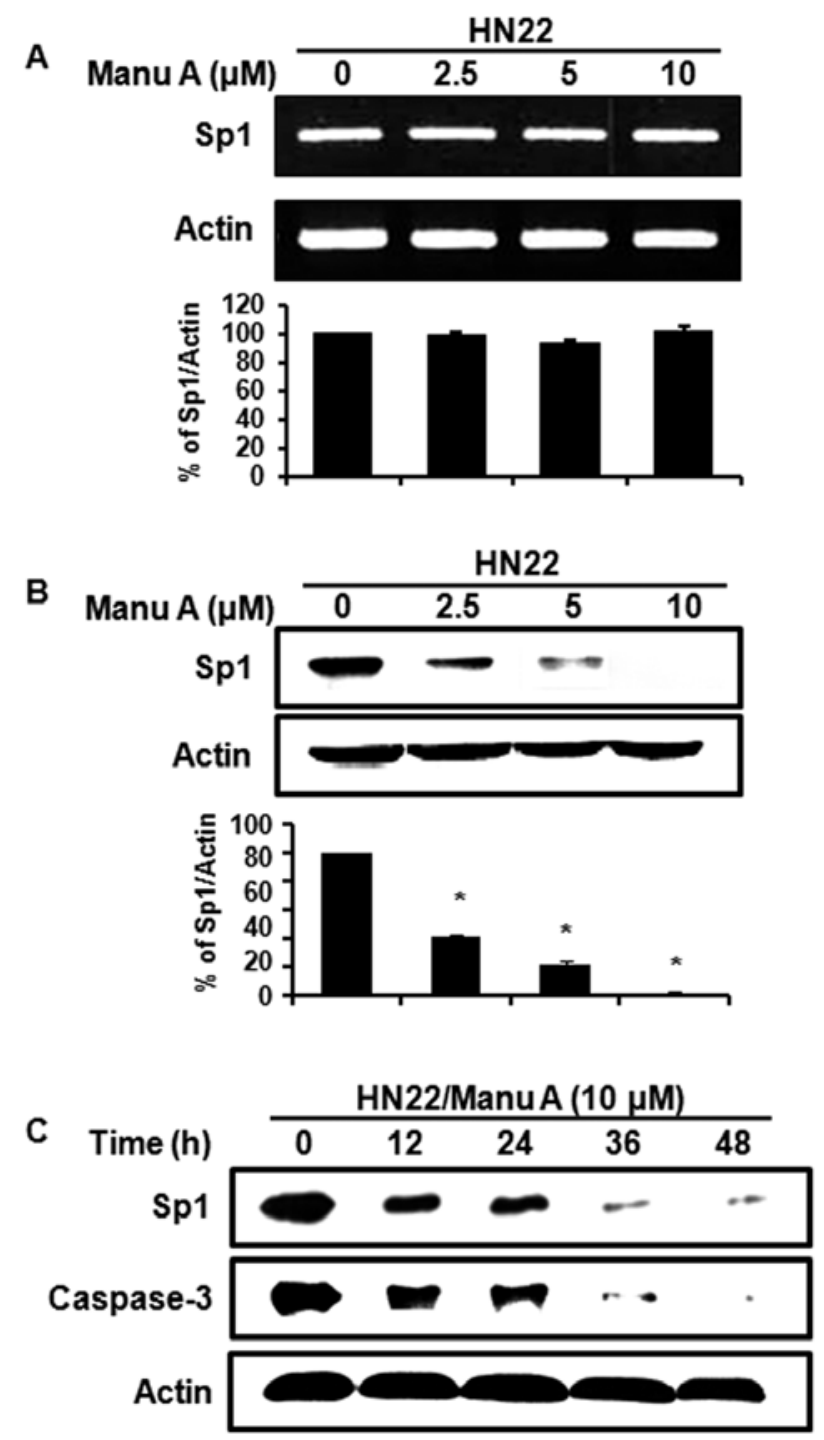
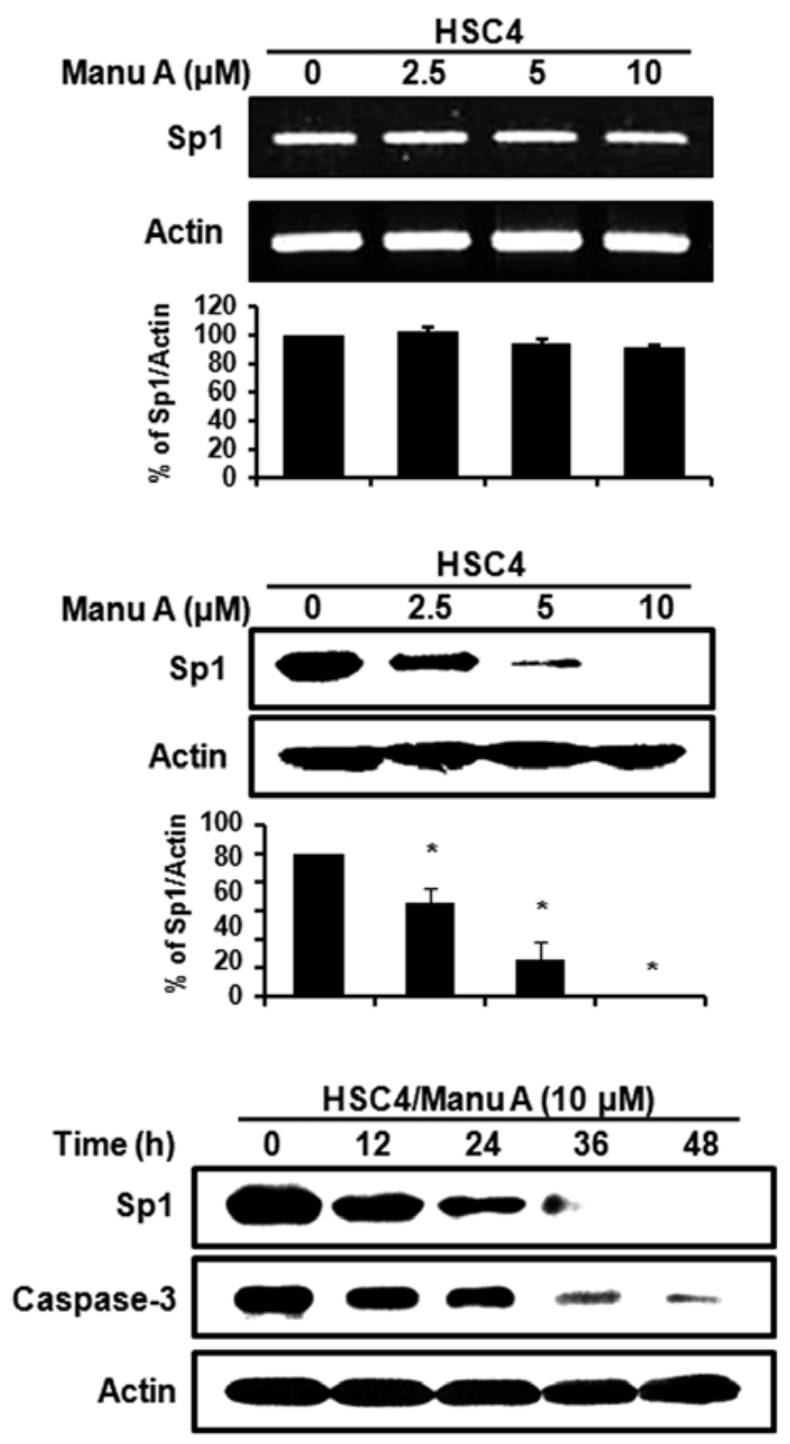

Figure 2. Manu A suppresses Sp1 proteins in OSCC cells and induces cell apoptosis. HN22 and HSC4 cells were treated with 2.5, 5 and $10 \mu$ M of Manu A for $48 \mathrm{~h}$. RT-PCR and western blot analysis were employed. The graphs indicate the mRNA (A) and protein (B) expression levels of Spl normalized to actin. (C) To examine the time-dependent effects of Manu A on Sp1 and caspase-3, HN22 and HSC4 cells were treated with $10 \mu$ M Manu A for 12, 24,36 and 48 h. Actin was included as the loading control.

these cells were incubated with $95 \mu$ l of Muse MitoPotential working solution that is diluted with $1 \mathrm{X}$ assay buffer $(1: 1,000)$ for $20 \mathrm{~min}$ in dark. Then, $5 \mu \mathrm{l}$ of Muse 7-AAD was added and samples were incubated at $37^{\circ} \mathrm{C}$ for $5 \mathrm{~min}$. Finally, all samples were analyzed by Muse Cell Analyzer (Merck Millipore).

Statistical analysis. Using Student's t-test, the statistical significance was assessed. The results with a P-value $<0.05$, was considered as statistically significant.

\section{Results}

Manu A inhibits human OSCC cell viability. Two OSCC cell lines HN22 and HSC4 were grown to investigate the effect of Manu A on OSCC cells. Manu A treatment significantly decreased cell viability in a dose- $(2.5,5$, and $10 \mu \mathrm{M})$ and time(24 and 48 h) dependent manner (Fig. 1B). Forty-eight hours after Manu A treatment, the viabilities of HN22 cells were, respectively, $91,57.8$ and $13.3 \%$ at $2.5,5$ and $10 \mu \mathrm{M}$ compared with control group and it showed significant decrease of cell viability in a dose-dependent manner. Similarly, the viabilities of HSC4 cells were, respectively, $71.8,46$, and $19.9 \%$ at 2.5 , 5 , and $10 \mu \mathrm{M}$ compared with control cells and it also showed the same dose-response as that in $\mathrm{HN} 22$. The $\mathrm{IC}_{50}$ values of Manu A for cell viability were 6.38 and $4.6 \mu \mathrm{M}$ in HN22 and HSC4, respectively.

Manu A induces apoptosis in human OSCC cells. We tested if Manu A could induce apoptosis of HN22 and HSC4 cells, using cell cycle analysis, DAPI staining, and double-staining of 7-AAD and Annexin V. The OSCC cells were treated with 2.5, 5 and $10 \mu \mathrm{M}$ of Manu A for $48 \mathrm{~h}$. Cell cycle analysis showed that Manu A induced sub-G $\mathrm{G}_{1}$ phase in $\mathrm{HN} 22$ and HSC4 cells in a dose-dependent manner (Fig. 1C). Especially, both of HN22 and HSC4 showed a significant increase in 
A

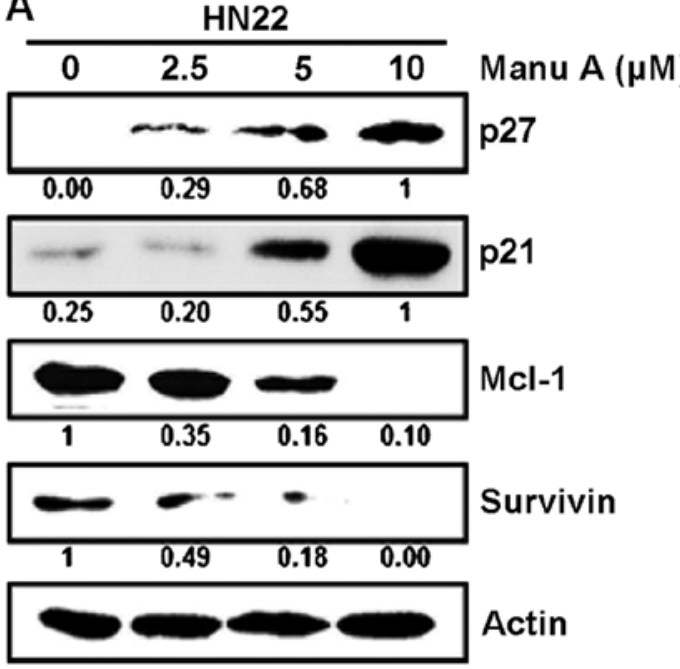

B

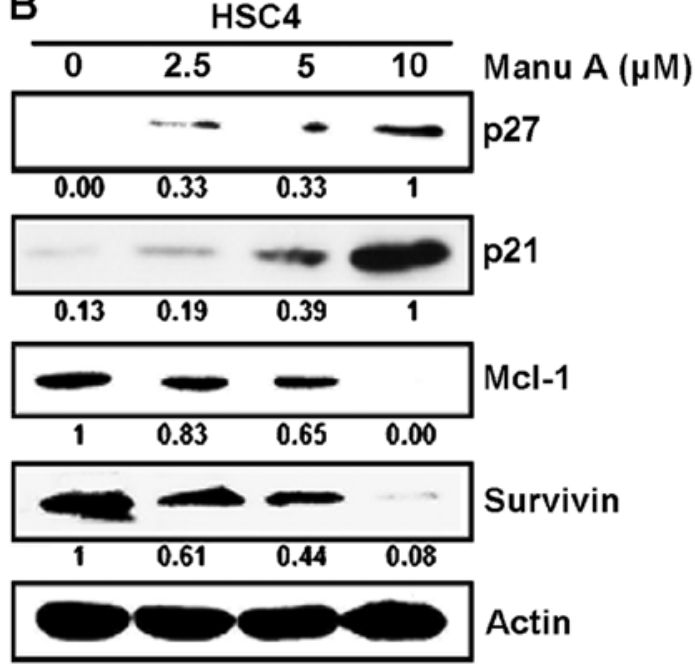

Figure 3. The effect of Manu A on Sp1 downstream target proteins in: (A) HN22 and (B) HSC4 cells treated with $2.5,5$ and $10 \mu$ M of Manu A. The effects of Manu A on p27, p21, Mcl-1 and survivin protein expression levels were determined by western blotting. The blots were re-probed with actin as a loading control.

sub- $\mathrm{G}_{1}$ phase and a decrease in $\mathrm{G}_{1}$ phase at $10 \mu \mathrm{M}$ of Manu $\mathrm{A}$, as compared to control groups. The proportion of sub- $\mathrm{G}_{1}$ phase increased from 3.8 \pm 0.4 (control) to $44.4 \pm 2.3 \%(10 \mu \mathrm{M})$ in HN22 cells (Fig. 1C, left) and also increased from 5.5 \pm 0.1 (control) to $45.3 \pm 1.9 \%(10 \mu \mathrm{M})$ in HSC4 cells (Fig. 1C, right). Further DAPI staining revealed the presence of nuclei condensation and apoptotic bodies in Manu A-treated OSCC cells (Fig. 1D). Moreover, 7-AAD and Annexin V doublestaining displayed an increased percentage of apoptotic cells after treatment with Manu A for $48 \mathrm{~h}$ in a dose-dependent manner (Fig. 5C and D).

Manu A regulates Spl and its target protein levels in human OSCC cells. Sp1 is a transcription factor of various genes that are essential to the regulation of cell survival, cell growth, cell cycle, and apoptosis (26-28). To investigate whether the Sp1-mediated apoptosis of OSCC cells might be caused by Manu A treatment or not, we used RT-PCR and western blotting in OSCC cells treated with Manu A $(2.5,5$, and $10 \mu \mathrm{M})$. As shown in Fig. 2A, there were no significant changes in the expression of Sp1 mRNA. However, the Sp1 protein levels in HN22 and HSC4 cells were decreased in a dose-dependent manner (Fig. 2B). We also monitored the protein levels of Sp1 and caspase-3 in OSCC cells (HN22 and HSC4) treated with $10 \mu \mathrm{M}$ of Manu A for various times $(0,12,24,36$ and $48 \mathrm{~h})$. The amounts of Sp1 were downregulated and also caspase-3 levels were significantly decreased with time by Manu A (Fig. 2C). Sp1 regulated the expression of its downstream targets such as p27, p21, Mcl-1, and survivin. The protein levels of cell cycle arrest proteins including p27 and p21 were elevated in HN22 (Fig. 3A) and HSC4 (Fig. 3B) by increasing doses of $(2.5,5$ and $10 \mu \mathrm{M}$ ) Manu A. On the contrary, cell proliferationand survival-related proteins like Mcl-1 and survivin were decreased in HN22 (Fig. 3A) and HSC4 (Fig. 3B).

Manu A induces cell stress and controls the mitochondrial membrane permeability during apoptosis. We investigated possible relationship between Manu A-induced cell stress and mitochondrial integrity. CHOP, death receptor 4 (DR4), and death receptor 5 (DR5) are related to endoplasmic reticulum (ER) stress. In a previous study, CHOP upregulated DRs (DR4 and DR5) by cell stress (29). The expression levels of CHOP, DR4, and DR5 were significantly increased in HN22 cells (Fig. 4C) and HSC4 cells (Fig. 4D) by Manu A. Changes of mitochondrial membrane permeability (MMP) are the common pathway of stress, triggering cell apoptosis (30). The members of Bcl-2 family regulate cell death by controlling the permeability of mitochondrial membrane (31).As judged from changes in MMP, total depolarized cell proportions were $5.6 \pm 0.2(2.5 \mu \mathrm{M}), 33.7 \pm 0.76(5 \mu \mathrm{M})$, and $80.0 \pm 0.61 \%(10 \mu \mathrm{M})$ in HN22 cells (Fig. 4A). In HSC4 cells (Fig. 4B), total depolarized cell proportions were $7.1 \pm 1.0(2.5 \mu \mathrm{M}), 36.3 \pm 0.4(5 \mu \mathrm{M})$ and $75.2 \pm 0.2 \%(10 \mu \mathrm{M})$.

Manu A modulates apoptosis-related proteins in OSCC cells. It has been reported that suppression of Sp1 induces apoptosis of cancer cells (32-34). To investigate molecular mechanism of Sp1-mediated apoptosis in HN22 cells (Fig. 5A) and HSC4 cells (Fig. 5B), we carried out western blot analysis of apoptosis-regulating proteins. Consequently, there was a decrease in levels of Bcl-2, Bid, Bcl-xl, and PARP in Manu A-treated OSCC cells. The levels of Bax and cleavage of PARP were elevated in a dose-dependent manner by Manu A. As shown in Fig. 5E and F, there was an increase of multi-caspase activity in both HN22 and HSC4 cells. As shown in Fig. 5E, the proportion of Multi-Caspase-positive HN22 cells was increased from $7.7 \pm 0.4(2.5 \mu \mathrm{M})$ to $15.5 \pm 1.2 \%(10 \mu \mathrm{M})$ and the population of caspase-positive/dead HN22 cells was increased from $18.9 \pm 1.0(2.5 \mu \mathrm{M})$ to $73.7 \pm 1.6 \%(10 \mu \mathrm{M})$. In HSC4 (Fig. 5F), the proportion of caspase-positive cells were $4.2 \pm 2.6,7.0 \pm 0.9$ and $2.1 \pm 0.2 \%$ of control cells while caspase-positive/dead cells were $12.1 \pm 0.6,29.5 \pm 1.4$ and $90.2 \pm 3.2 \%$ of control cells at $2.5,5$ and $10 \mu \mathrm{M}$ of Manu A, respectively. As a whole, suppression of Sp1 by Manu A induces apoptosis in OSCC cells. 
HN22

A

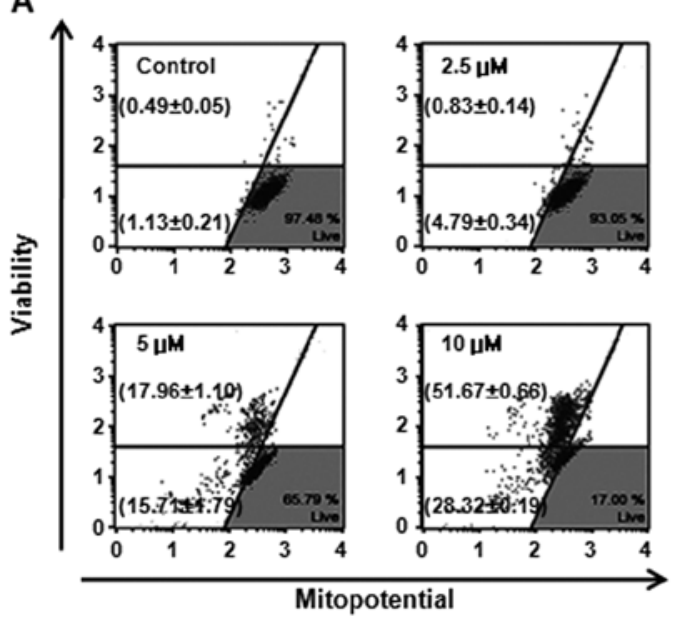

C

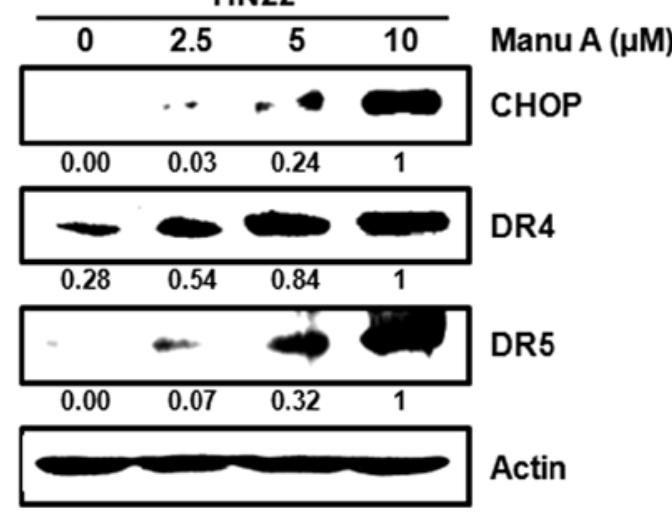

HSC4

B

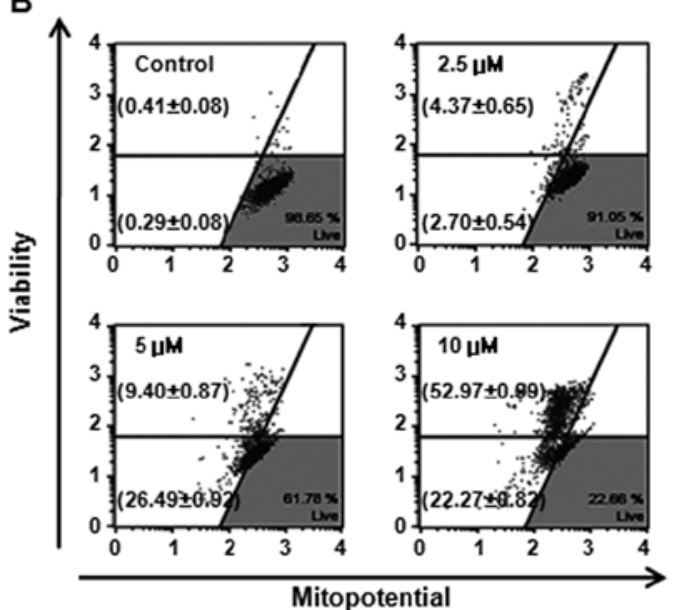

D

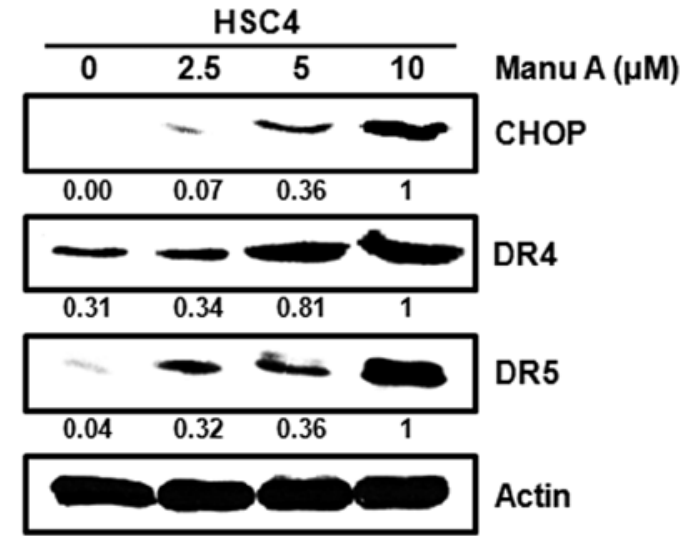

Figure 4. Increased expression levels of the death receptor proteins and induction of mitochondrial dysfunction by Manu A induced cell apoptosis. Depolarization profiles of the mitochondrial membrane are shown in plots (A and B). The data represent the mean percentage levels \pm SD ( $=3$ ). The expression levels of CHOP and death receptor proteins (DR4 and DR5) were analyzed by western blotting in HN22 (C) and HSC4 (D) cells. Actin was used as the loading control.

\section{Discussion}

Oral cancer is a subtype of head and neck cancer and its 5 -year survival rate has been slightly improved over the last few decades in spite of advanced cancer diagnosis or therapies (radiotherapy, chemotherapy, and surgery) (35). Recent studies revealed that some antibiotics not only reduce cell proliferation but also induce apoptosis on human cancer cells $(36,37)$. We examined Manu A, a natural antibiotics and tumoricide, as a new potential candidate substance for OSCC chemotherapy. In our study, we investigated whether Manu A could reduce cell proliferation and induce apoptosis through Sp1 regulation in OSCC cell lines (HN22 and HSC4). First of all, we tested anti-proliferation effect of Manu A using MTS assay. Treatment of cells with various concentration of Manu A exhibited a significant decrease in cell viability in a dosedependent manner. PI staining was performed to find any link of Manu A-mediated cell cycle regulation to cell apoptosis. We observed remarkable increase in proportion of sub- $\mathrm{G}_{1}$ in a dose-dependent manner. Furthermore, both cell anlayses of cells stained with 7-AAD and Annexin V and measurement of caspase activity demonstrated dose-dependent apoptotic effects of Manu A. Taken together, the data described above, Manu A has biological effects on OSCC cells with respect to cell growth and death.

$\mathrm{Sp} 1$ is a zinc finger transcription factor that binds to GC-rich motifs of many promoters (38) and has been reported to affect the tumorigenesis of many cancers including angiogenesis, cell cycle progression and inflammation (38). To prove that the cell apoptosis by Manu A is mediated by Sp1 regulation, we performed RT-PCR and western blotting. Although the expression of Sp1 mRNA was not decreased, the Sp1 protein levels were significantly downregulated by Manu A in a dose- and time-dependent manner. To further investigate molecular mechanism of Sp1-mediated cell apoptosis, we also examined the expression levels of $\mathrm{Sp} 1$ target proteins such as p21, p27, Mcl-1, and survivin. It was demonstrated that regulators of cell cycle progression such as p21, p27 $(39,40)$ were increased. It is known that p27 binds to and prevents the activation of cyclin E-cyclin-dependent kinase 2 (CDK2) or cyclin D-cyclin-dependent kinase 4 (CDK4) complexes (41). During the cell division, p27 acts as a cell cycle inhibitor. Similarly, p21 protein binds to and inhibits the complexes of cyclin-CDKs (CDK2, CDK3, CDK4, or CDK6) and thus acts 
A

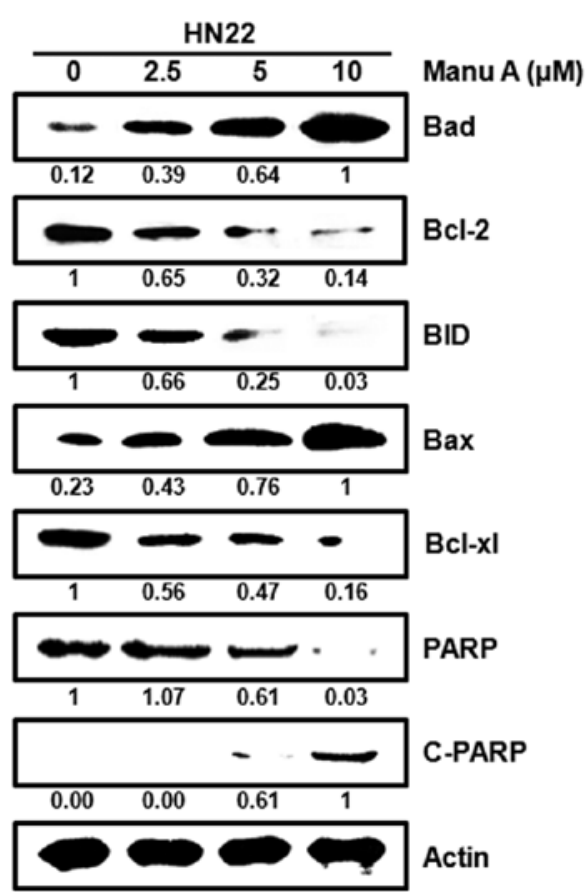

C

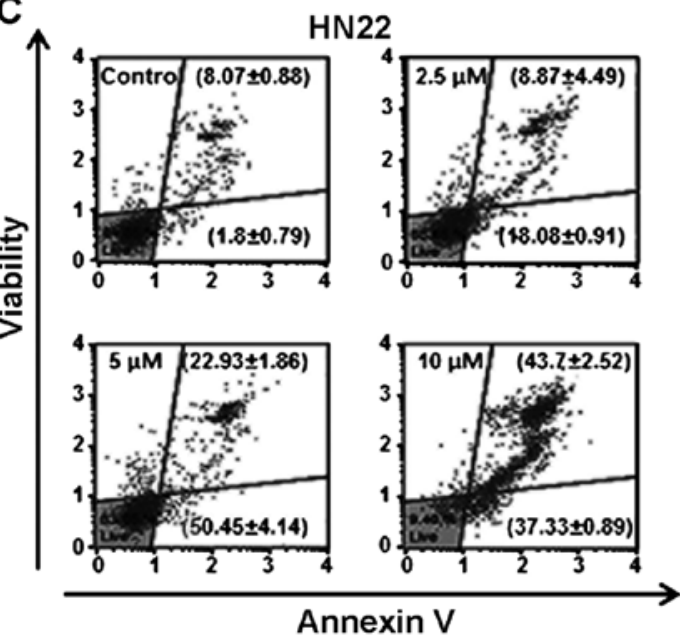

$E$

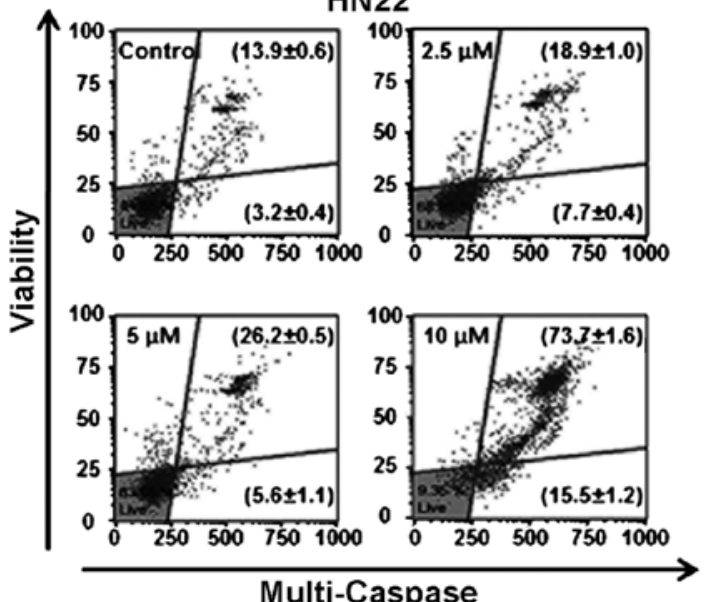

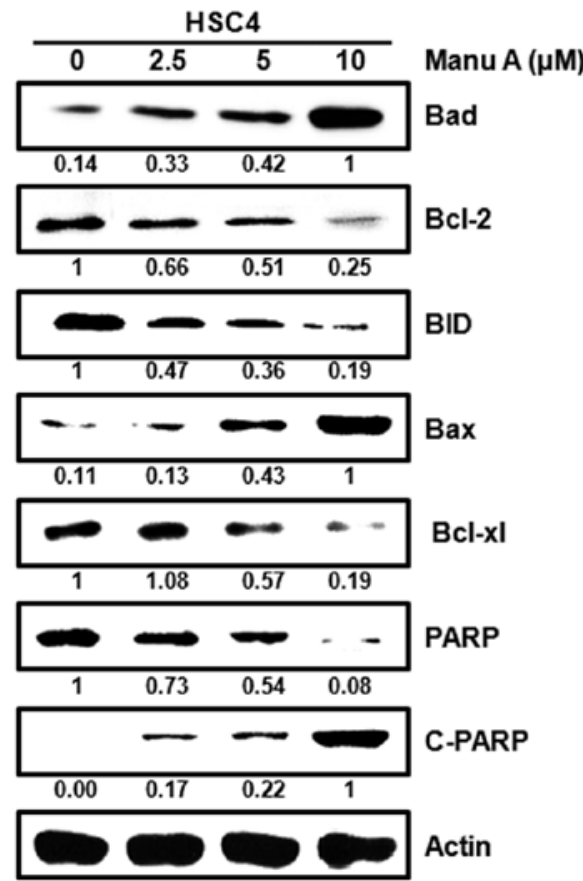

D

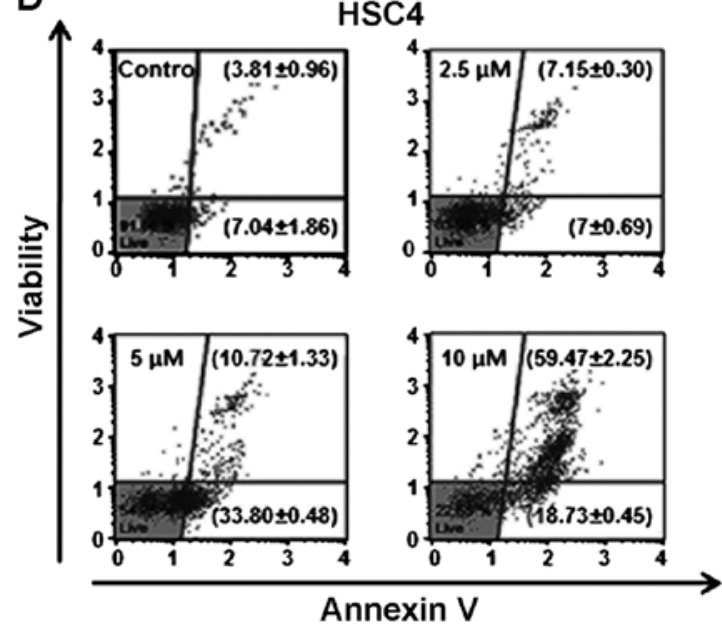

F

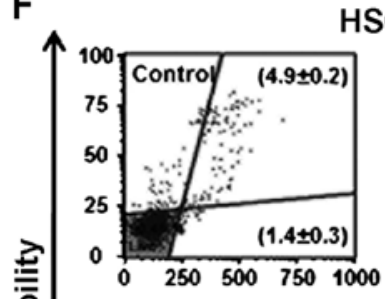

HSC4
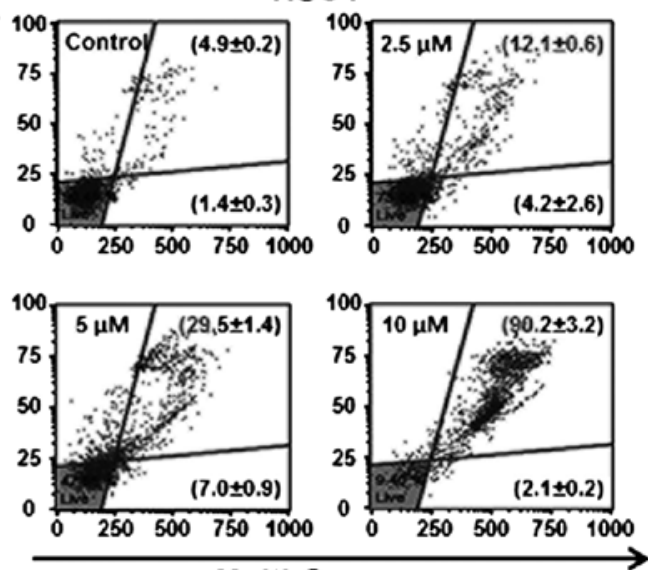

Multi-Caspase

Figure 5. The effects of Manu A on expression of proteins associated with apoptosis in OSCC cells. HN22 (A) and HSC4 (B) cells were treated with 2.5, 5 and $10 \mu \mathrm{M}$ of Manu A for $48 \mathrm{~h}$ and analyzed by western blotting using antibodies against Bad, Bcl-2, BID, Bax, Bcl-xl, PARP and C-PARP. Actin was used to normalize the protein bands. Induction of apoptosis in OSCC cells by Manu A was quantitated as determined by Muse Cell Analyzer. The plots indicate HN22 (C and E) and HSC4 (D and F) cells after exposure to 2.5, 5 and $10 \mu \mathrm{M}$ of Manu A for $48 \mathrm{~h}$. The analyzer profiles were made after Annexin V (C and D) and Multi-Caspase staining (E and F). (C and D) The number represents the percentage of early to mid apoptotic cells (lower right quadrant) and late apoptotic/ dying cells (upper right quadrant). (E and F) Each quadrant indicates caspase-positive, caspase-positive/dead and dead in the counter-clockwise rotation. The results shown are representative of three independent experiments. The data represent the mean percentage levels \pm SD $(n=3)$. 
as a cell cycle inhibitor (42). Anti-apoptosis factors such as Mcl-1, and survivin were diminished by Manu A. As a member of Bcl-2 family, Mcl-1 is overexpressed in many human cancers and plays an important role in acquiring resistance to apoptosis (43). The inhibitors of apoptosis (IAP), survivin suppresses the apoptosis and its overexpression is associated with development of human cancer (44). Accordingly, it can be summarized that Manu A induces apoptotic pathways in OSCC cells through regulation of $\mathrm{Sp} 1$ and its target proteins (p21, p27, Mcl-1 and survivin).

In response to stress, cell initiates cell death signaling through the intrinsic and the extrinsic pathways. Intrinsic pathway involves mitochondrial involvement when exposed to death stimuli. Mitochondria produce energy that the cell needs by oxidative phosphorylation process on the inner membrane. In many pathophysiological context, cell fate is dependent on Bcl-2 family members (45). Bax is a pro-apoptotic Bcl-2 family member and accelerates the opening of voltagedependent anion channel (VDAC) and Bad, pro-apoptotic Bcl-2 family member, allowing Bax-triggered apoptosis interacting with Bcl-2 and Bcl-xl (46-48). Opening VDAC pore activates death-driving proteolytic proteins known as caspase (30) beginning with cleavage of PARP (49). Whereas, anti-apoptotic Bcl-family members such as Bcl-2 and Bcl-xl inhibit opening the VDAC pore (50). Manu A treatment facilitated pro-apoptotic proteins (Bax and Bad) and cleaved PARP while a decrease in anti-apoptotic proteins (Bcl-2 and $\mathrm{Bcl}-\mathrm{xl})$ was also observed by Manu A treatment. Considering the data associated with mitochondrial membrane potential, Manu A induces apoptosis through the intrinsic pathway in OSCC cells, whereas, the extrinsic pathway starts with stimulation of tumor necrosis factor (TNF) receptor superfamily including TNF-related apoptosis-inducing ligand (TRAIL) receptor (51). DR4 (TRAIL-R1 for TNF-related apoptosis-inducing ligand receptor-1) and DR5 (TRAIL-R2) interact with its cognate ligand and share common signaling mechanism that activates caspase-8 (52) and increased C/EBP homologous protein (CHOP) elevates DR5 expression (53). Because caspase- 8 catalyzes cleavage of $\mathrm{BH} 3$-only protein (Bid) to t-Bid that facilitates the release of mitochondrial proteins into cytosol and it has been reported that $\mathrm{CHOP}$ downregulates Bcl-2 expression and sensitizes the cell to ER stress (29), extrinsic pathway incorporating the part of intrinsic apoptotic pathway (54). We found that CHOP, DR4, and DR5 were overexpressed in a dose-dependent manner while Bid was downregulated in Manu A-treated OSCC cells. These results revealed that Manu A induces cell apoptosis through not only the intrinsic pathway, but also the extrinsic pathway.

Based on the effects of Manu A in OSCC cells, we conclude that Manu A downregulates Sp1 protein levels, which in turn induces cell apoptosis of OSCC cells (HN22 and HSC4) through both the intrinsic and the extrinsic pathways. Therefore, the use of Manu A may be a novel therapy for OSCC patients with overexpression of Sp1 protein.

\section{Acknowledgements}

This study was supported by Basic Science Research program through the National Research Foundation Korea (NRF) funded by the Ministry of Education, Science and
Technology (2014R1A1A2053500) and the Next-Generation BioGreen 21 Program (PJ01116401) from Rural Development Administration, Republic of Korea.

\section{References}

1. Jemal A, Bray F, Center MM, Ferlay J, Ward E and Forman D: Global cancer statistics. CA Cancer J Clin 61: 69-90, 2011.

2. Rivera $\mathrm{C}$ and Venegas B: Histological and molecular aspects of oral squamous cell carcinoma (Review). Oncol Lett 8: 7-11, 2014.

3. Nagpal JK, Patnaik S and Das BR: Prevalence of high-risk human papilloma virus types and its association with P53 codon 72 polymorphism in tobacco addicted oral squamous cell carcinoma (OSCC) patients of Eastern India. Int J Cancer 97: 649-653, 2002.

4. Wang J, Jia L, Kuang Z, Wu T, Hong Y, Chen X, Leung WK, Xia J and Cheng B: The in vitro and in vivo antitumor effects of clotrimazole on oral squamous cell carcinoma. PLoS One 9: e98885, 2014.

5. Johnson NW, Jayasekara P and Amarasinghe AA: Squamous cell carcinoma and precursor lesions of the oral cavity: Epidemiology and aetiology. Periodontol 2000 57: 19-37, 2011.

6. Parkin DM, Bray F, Ferlay J and Pisani P: Global cancer statistics, 2002. CA Cancer J Clin 55: 74-108, 2005.

7. Yuan P, Temam S, El-Naggar A, Zhou X, Liu DD, Lee JJ and Mao L: Overexpression of podoplanin in oral cancer and its association with poor clinical outcome. Cancer 107: 563-569, 2006.

8. Forastiere A, Koch W, Trotti A and Sidransky D: Head and neck cancer. N Engl J Med 345: 1890-1900, 2001.

9. Sano D and Myers JN: Metastasis of squamous cell carcinoma of the oral tongue. Cancer Metastasis Rev 26: 645-662, 2007.

10. Silverman S Jr: Demographics and occurrence of oral and pharyngeal cancers. The outcomes, the trends, the challenge. J Am Dent Assoc 132 (Suppl): S7S-S11, 2001.

11. Gervásio OL, Dutra RA, Tartaglia SM, Vasconcellos WA, Barbosa AA and Aguiar MC: Oral squamous cell carcinoma: A retrospective study of 740 cases in a Brazilian population. Braz Dent J 12: 57-61,2001.

12. Bundgaard T, Bentzen SM and Wildt J: The prognostic effect of tobacco and alcohol consumption in intra-oral squamous cell carcinoma. Eur J Cancer B Oral Oncol 30B: 323-328, 1994.

13. Lissowska J, Pilarska A, Pilarski P, Samolczyk-Wanyura D, Piekarczyk J, Bardin-Mikolłajczak A, Zatonski W, Herrero R, Munoz N and Franceschi S: Smoking, alcohol, diet, dentition and sexual practices in the epidemiology of oral cancer in Poland. Eur J Cancer Prev 12: 25-33, 2003.

14. Zhou JM, Zhu XF, Pan QC, Liao DF, Li ZM and Liu ZC: Manumycin inhibits cell proliferation and the Ras signal transduction pathway in human hepatocellular carcinoma cells. Int J Mol Med 11: 767-771, 2003.

15. Frassanito MA,Cusmai A,Piccoli C and Dammacco F: Manumycin inhibits farnesyltransferase and induces apoptosis of drug-resistant interleukin 6-producing myeloma cells. Br J Haematol 118: 157-165, 2002.

16. Di Paolo A, Danesi R, Nardini D, Bocci G, Innocenti F, Fogli S, Barachini S, Marchetti A, Bevilacqua G and Del Tacca M: Manumycin inhibits ras signal transduction pathway and induces apoptosis in COLO320-DM human colon tumour cells. Br J Cancer 82: 905-912, 2000.

17. Li JG, She MR, Lu CY, Wei SS, Xia PF, Lu ZS and Peng Q: Manumycin induces apoptosis in prostate cancer cells. Onco Targets Ther 7: 771-777, 2014.

18. Xiong Q and Rikihisa Y: The prenylation inhibitor manumycin A reduces the viability of Anaplasma phagocytophilum. J Med Microbiol 60: 744-749, 2011.

19. Devanand P, Kim SI, Choi YW, Sheen SS, Yim H, Ryu MS, Kim SJ, Kim WJ and Lim IK: Inhibition of bladder cancer invasion by Sp1-mediated BTG2 expression via inhibition of DNA methyltransferase 1. FEBS J 281: 5581-5601, 2014.

20. Krishnan V, Wang X and Safe S: Estrogen receptor-Sp1 complexes mediate estrogen-induced cathepsin D gene expression in MCF-7 human breast cancer cells. J Biol Chem 269: 15912-15917, 1994.

21. Chuang CW, Pan MR, Hou MF and Hung WC: Cyclooxygenase-2 up-regulates CCR7 expression via AKT-mediated phosphorylation and activation of $\mathrm{Spl}$ in breast cancer cells. J Cell Physiol 228: 341-348, 2013.

22. Banerjee S, Sangwan V, McGinn O, Chugh R, Dudeja V, Vickers SM and Saluja AK: Triptolide-induced cell death in pancreatic cancer is mediated by O-GlcNAc modification of transcription factor Sp1. J Biol Chem 288: 33927-33938, 2013. 
23. Guo MM, Hu LH, Wang YQ, Chen P, Huang JG, Lu N, He JH and Liao CG: miR-22 is down-regulated in gastric cancer, and its overexpression inhibits cell migration and invasion via targeting transcription factor Sp1. Med Oncol 30: 542, 2013.

24. Singha PK, Pandeswara S, Venkatachalam MA and Saikumar P: Manumycin A inhibits triple-negative breast cancer growth through LC3-mediated cytoplasmic vacuolation death. Cell Death Dis 4: e457, 2013.

25. Courey AJ and Tjian R: Analysis of Sp1 in vivo reveals multiple transcriptional domains, including a novel glutamine-rich activation motif. Cell 55: 887-898, 1988.

26. Lu S and Archer MC: Spl coordinately regulates de novo lipogenesis and proliferation in cancer cells. Int J Cancer 126 : 416-425, 2010

27. Opitz OG and Rustgi AK: Interaction between Sp1 and cell cycle regulatory proteins is important in transactivation of a differentiation-related gene. Cancer Res 60: 2825-2830, 2000.

28. Wang L, Wei D, Huang S, Peng Z, Le X, Wu TT, Yao J, Ajani J and Xie K: Transcription factor $\mathrm{Spl}$ expression is a significant predictor of survival in human gastric cancer. Clin Cancer Res 9: 6371-6380, 2003.

29. Yamaguchi H and Wang HG: CHOP is involved in endoplasmic reticulum stress-induced apoptosis by enhancing DR5 expression in human carcinoma cells. J Biol Chem 279: 45495-45502, 2004

30. Shimizu S, Narita M and Tsujimoto Y: Bcl-2 family proteins regulate the release of apoptogenic cytochrome $c$ by the mitochondrial channel VDAC. Nature 399: 483-487, 1999.

31. Yang J, Liu X, Bhalla K, Kim CN, Ibrado AM, Cai J, Peng TI, Jones DP and Wang X: Prevention of apoptosis by Bcl-2: Release of cytochrome $c$ from mitochondria blocked. Science 275 1129-1132, 1997.

32. Sankpal UT, Goodison S, Abdelrahim M and Basha R: Targeting Sp1 transcription factors in prostate cancer therapy. Med Chem 7: 518-525, 2011

33. Chintharlapalli S, Papineni S, Ramaiah SK and Safe S: Betulinic acid inhibits prostate cancer growth through inhibition of specificity protein transcription factors. Cancer Res 67: 2816-2823 2007.

34. Jutooru I, Chadalapaka G, Sreevalsan S, Lei P, Barhoumi R, Burghardt $\mathrm{R}$ and Safe S: Arsenic trioxide downregulates specificity protein $(\mathrm{Sp})$ transcription factors and inhibits bladder cancer cell and tumor growth. Exp Cell Res 316: 2174-2188, 2010.

35. Choi ES, Cho SD, Jeon JG and Cho NP: The apoptotic effect of the hexane extract of Rheum undulatum L. in oral cancer cells through the down-regulation of specificity protein 1 and survivin. Lab Anim Res 27: 19-24, 2011.

36. Bhat UG, Halasi $M$ and Gartel AL: Thiazole antibiotics target FoxM1 and induce apoptosis in human cancer cells. PLoS One 4: e5592, 2009.

37. Basso AD, Solit DB, Munster PN and Rosen N: Ansamycin antibiotics inhibit Akt activation and cyclin $\mathrm{D}$ expression in breast cancer cells that overexpress HER2. Oncogene 21: 1159-1166, 2002.

38. Nakano K, Mizuno T, Sowa Y, Orita T, Yoshino T, Okuyama Y, Fujita T, Ohtani-Fujita N, Matsukawa Y, Tokino T, et al: Butyrate activates the WAF1/Cip1 gene promoter through Sp1 sites in a p53-negative human colon cancer cell line. J Biol Chem 272: 22199-22206, 1997.
39. Toyoshima $\mathrm{H}$ and Hunter T: p27, a novel inhibitor of G1 cyclinCdk protein kinase activity, is related to p21. Cell 78: 67-74, 1994.

40. Yoon MK, Mitrea DM, Ou L and Kriwacki RW: Cell cycle regulation by the intrinsically disordered proteins p21 and p27. Biochem Soc Trans 40: 981-988, 2012.

41. Lee TH, Chang HC, Chuang LY and Hung WC: Involvement of PKA and Sp1 in the induction of p27(Kip1) by tamoxifen. Biochem Pharmacol 66: 371-377, 2003.

42. Neto AG, McCutcheon IE, Vang R, Spencer ML, Zhang W and Fuller GN: Elevated expression of p21 (WAF1/Cip1) in hormonally active pituitary adenomas. Ann Diagn Pathol 9: 6-10, 2005.

43. Quinn BA, Dash R, Azab B, Sarkar S, Das SK, Kumar S, Oyesanya RA, Dasgupta S, Dent P, Grant S, et al: Targeting Mcl-1 for the therapy of cancer. Expert Opin Investig Drugs 20 : 1397-1411, 2011.

44. Tanaka C, Uzawa K, Shibahara T, Yokoe H, Noma H and Tanzawa H: Expression of an inhibitor of apoptosis, survivin, in oral carcinogenesis. J Dent Res 82: 607-611, 2003.

45. Li H, Zhu H, Xu CJ and Yuan J: Cleavage of BID by caspase 8 mediates the mitochondrial damage in the Fas pathway of apoptosis. Cell 94: 491-501, 1998.

46. Heibein JA, Goping IS, Barry M, Pinkoski MJ, Shore GC, Green DR and Bleackley RC: Granzyme B-mediated cytochrome $c$ release is regulated by the $\mathrm{Bcl}-2$ family members bid and Bax. J Exp Med 192: 1391-1402, 2000.

47. Kelekar A, Chang BS, Harlan JE, Fesik SW and Thompson CB: $\mathrm{Bad}$ is a $\mathrm{BH} 3$ domain-containing protein that forms an inactivating dimer with Bcl-XL. Mol Cell Biol 17: 7040-7046, 1997.

48. Hsu SY, Kaipia A, Zhu L and Hsueh AJ: Interference of BAD (Bcl-xL/Bcl-2-associated death promoter)-induced apoptosis in mammalian cells by 14-3-3 isoforms and P11. Mol Endocrinol 11: 1858-1867, 1997.

49. Kharbanda S, Pandey P, Schofield L, Israels S, Roncinske R, Yoshida K, Bharti A, Yuan ZM, Saxena S, Weichselbaum R, et al: Role for Bcl-xL as an inhibitor of cytosolic cytochrome $C$ accumulation in DNA damage-induced apoptosis. Proc Nat Acad Sci USA 94: 6939-6942, 1997.

50. Marzo I, Brenner C, Zamzami N, Susin SA, Beutner G, Brdiczka D, Rémy R, Xie ZH, Reed JC and Kroemer G: The permeability transition pore complex: A target for apoptosis regulation by caspases and bcl-2-related proteins. J Exp Med 187: 1261-1271, 1998.

51. Fulda S and Debatin KM: Extrinsic versus intrinsic apoptosis pathways in anticancer chemotherapy. Oncogene 25: 4798-4811, 2006.

52. Beurel E and Jope RS: The paradoxical pro- and anti-apoptotic actions of GSK3 in the intrinsic and extrinsic apoptosis signaling pathways. Prog Neurobiol 79: 173-189, 2006.

53. Moon DO, Park SY, Choi YH, Ahn JS and Kim GY: Guggulsterone sensitizes hepatoma cells to TRAIL-induced apoptosis through the induction of CHOP-dependent DR5: Involvement of ROS-dependent ER-stress. Biochem Pharmacol 82: 1641-1650, 2011

54. Luo X, Budihardjo I, Zou H, Slaughter C and Wang X: Bid, a $\mathrm{Bcl} 2$ interacting protein, mediates cytochrome $c$ release from mitochondria in response to activation of cell surface death receptors. Cell 94: 481-490, 1998. 